\title{
Trabalhar em equipe: de que equipe e de que trabalho falamos?
}

\author{
Dominique Efros*
}

\begin{abstract}
Resumo
Os aspectos coletivos de uma atividade de trabalho são tanto observáveis quanto invisíveis, formalmente prescritos quanto clandestinos, formalizados e referenciados quando indizíveis ou inclassificáveis, e a noção de "trabalho em equipe" reduz consideravelmente o campo de análise do que pode ser a eficácia coletiva. Conhecimentos gerais e saberes práticos devem ser conjugados para progredir na análise do que as práticas coletivas produzem.
\end{abstract}

Palavras-chave: Atividade de trabalho. Trabalho em equipe. Coletivo. Cooperação.

P ode-se considerar que as atividades de cuidados hospitalares são tão particulares, que os conhecimentos forjados em outros meios profissionais não são de nenhuma utilidade. Mas se decidimos considerar essas atividades como formas de atividade humana, então algumas "comensurabilidades" podem alimentar a reflexão. ${ }^{1}$ Assim, o que sabemos sobre o que se chama "trabalho de equipe"? O que dizer dos "aspectos coletivos" de um trabalho? A abordagem ergológica das situações de trabalho permitiu forjar um conceito, "as entidades coletivas relativamente pertinentes" (ECRP), que abre o horizonte sobre uma maneira de apreender os processos de cooperação que atuam na realização de toda atividade e que pode contribuir para os debates atuais sobre a evolução das profissóes hospitalares e das práticas de gestão.

\footnotetext{
Tradução feita por Mônica Soares Beato, com base na versão francesa publicada em 2004, no número 49 da Revista Soins Cadres, Paris, Editions Masson.

* Socióloga, Institut d’Ergologie-CEPERC, Aix-Marseille Université.

1 O termo "comensurabilidades" permite esvaziar toda uma ideia de comparação termo a termo, apontando para o fato de que, em certa medida, pode haver coisas parecidas em seu princípio e que encontramos em situaçōes de trabalho concretas totalmente diferentes.
} 


\section{As fronteiras dessas ecrp são sempre singulares}

Contrariamente às "equipes", às "unidades" de trabalho orientadas pelas categorias socioprofissionais (enfermeira, aide-soignante, ${ }^{2}$ agente de serviço hospitalar, ${ }^{3}$ secretária) ou por categorias organizacionais e hierárquicas (funçōes e responsabilidades esquematizadas em um organograma), as ECRP não preexistem à implementação de atos de trabalho; são as necessidades do "trabalhar junto" que as fazem existir de maneiras diferentes segundo os momentos.

Assim, em um atelier de produção a "todo vapor", a equipe de base era composta de três operadores, mas os contornos do coletivo operacional variavam. Durante o dia, os contatos e as trocas com os membros da hierarquia se multiplicavam, a hierarquia estando mais "encorpada" do que durante a noite; era preciso integrar pontualmente a atividade dos operadores de manutenção, garantir a segurança dos trabalhos que eles efetuavam sobre as instalaçôes. Em geral, a colaboração com os motoristas dos caminhōes-tanque, salariados por uma empresa exterior, encarregados de esvaziar o produto a jusante, era mais frequente do que com os operadores da oficina a montante, que forneciam a matéria para trabalhar. ${ }^{4}$ Em um serviço de neurologia, a análise da atividade de uma equipe de cuidados mostrou que ao efetivo oficial era preciso acrescentar pessoas que, mesmo sem ter, necessariamente, competência médica ou terapêutica, participavam concretamente da atividade e da eficácia da equipe. Tal era o caso da secretária, no centro das relações entre os doentes e suas famílias, entre a equipe médica e a equipe de cuidados, entre o serviço e os outros serviços do hospital. O pessoal paramédico (psicólogo, fisioterapeuta) participava igualmente da eficácia coletiva já que ele trazia elementos de conhecimento sobre os pacientes. ${ }^{5}$ Uma ECRP não está, então, calcada sobre um coletivo predefinido. Seus contornos variam conforme o conteúdo e o ritmo da atividade de trabalho, o que justifica o uso do termo "entidade", que designa essa indeterminação a priori.

\footnotetext{
Nota da tradutora: embora a expressão seja comumente traduzida para o português como auxiliar de enfermagem, trata-se de uma profissão não existente no Brasil, com outra formação em relação ao auxiliar de enfermagem, aproximando-se de um cuidador.

N.T.: equivalente, no Brasil, ao auxiliar de serviços gerais ou de limpeza.

Charriaux, M-M., (19--?). Qualifications en procès. Situations de travail qualifiantes à Péchiney-Gardanne. Rapport de recherche. Université de Provence.

Fouilleul, N., Matheron, G. (1996). Construction collective de l'efficacité dans une unité de soins. Gestions hospitalières, $360,668-672$.
} 


\section{A dimensão coletiva não é sempre aparente}

Pode-se considerar que um coletivo de trabalho não é mais eficaz acima de quinze membros? Não seria reduzir, automaticamente, as múltiplas relaçôes requisitadas e permitidas pelas situaçōes de trabalho? A densidade e a materialidade dessas relações cobrem um largo leque de possibilidades.

Tomemos o exemplo do condutor de trem SNCF, sozinho, em sua cabine. O agente pode conduzir seu trem "progressivamente"6 ou ser adepto da "marcha lenta" 7 No primeiro caso, a velocidade é mantida ao máximo autorizado em todo lugar onde isso é possível, até a ação in extremis sobre os meios técnicos de frenagem, a argumentação recai sobre o ganho de tempo; no segundo caso, ao contrário, os agentes escolhem diminuir a velocidade antecipadamente, para apenas exercer uma ação insensível sobre os meios de frenagem, a atenção é mais centrada sobre o conforto dos viajantes. Podese então dizer que "o ator individual, pela natureza das escolhas operadas, pela forma como ele reúne os elementos de eficácia de sua própria ação, manifesta assim seu pertencimento a uma ou outra das influências desse coletivo inaparente". ${ }^{8}$ Esses "gestos naturais da profissão" fazem parte das relações entre os pares.

Atos exercidos sozinhos podem ser também indiretamente endereçados aos membros ausentes de um coletivo. Assim, a análise da atividade de uma aide-soignante na chegada de pacientes em um serviço de cirurgia cardíaca valorizou o trabalho de "enraizamento simbólico" do doente no serviço, trabalho que ela conduz pelo ritual de instalação e efetuação de um "protocolo psicológico". A Aide-soignante recolhe as informaçoes, falando com o paciente, consultando seu prontuário ou telefonando para a supervisora; ela as transcreve na ficha de reanimação e na ficha de temperatura; ela realiza alguns atos, como a pesagem, a raspagem e, sobretudo, ela observa as reaçõos do paciente enquanto ela evoca a operação que está por vir. Um tipo de tabela informal funciona, permitindo a repartição dos "entrantes" 10 em três categorias: o doente estressado, fechado em seu silêncio, o contente de ser operado, o nervoso que não se satisfaz com nada. Essas categorias

\footnotetext{
6 N.T.: em francês, "par palier”.

N.T.: em francês, “marche sur l'erre”. Num navio, a expressão significa sua velocidade residual quando não há mais propulsão; continuar a avançar sem propulsão.

8 Faïta, D. (1997). In Y. Schwartz. Reconnaissances du travail, pour une approche ergologique. (pp. 52-53). Paris: PUF.

Doray, B, Clot, Y, Michel (19--?), A. La gestion à coeur : approche de l'efficacité dans le service de chirurgie cardiaque de la Pitié-Salpétrière. In Y. Schwartz. L'évaluation économique à l'épreuve des services. Rapport de recherche, Université de Provence.

${ }^{10}$ N.T.: em francês, "entrant": doente que acaba de ser admitido num serviço hospitalar.
} 
"compiladas em lugar algum" completam as indicações da supervisora e servirão para definir uma ordem de passagem ao bloco. "No plano de fundo do primeiro interlocutor, que é sempre o paciente, os protocolos psicológicos atuantes no trabalho da aide-soignante endereçam-se também aos outros profissionais do serviço". Todos desenvolvem igualmente o que se poderia designar como uma "clínica operacional de cuidados", clínica baseada sobre o trabalho que o paciente deve fazer com respeito à sua própria situação.

Em termos de metodologia de análise, observa-se aí, de modo evidente, que é impossível apreender finamente relações sem debater com os principais interessados, únicos que podem ajudar a aclarar esses laços invisíveis. Mas esse princípio de coconstrução para definir e interpretar atos e situaçôes de trabalho revela-se incontornável, o que quer que se procure conhecer, a partir do momento em que concordamos em reconhecer que, em Ciências Humanas e Sociais, cada um é, ao mesmo tempo, juiz e parte e que a objetividade "pura" não existe.

\section{As tarefas redistribuem-se em função de múltiplos critérios}

O tempo, o espaço, o objeto de trabalho, a natureza das operações e os procedimentos a realizar, o objetivo em curto ou médio prazo da atividade, tantos elementos para caracterizar uma situação na qual vários indivíduos atuam. A coatividade reúne, em um mesmo espaço, os profissionais de diferentes especialidades que têm objetivos diferentes; a cooperação supõe, por outro lado, que os indivíduos ajam juntos sobre o mesmo objeto de trabalho, visando ao mesmo "objetivo proximal"; na colaboração, os indivíduos não realizam as mesmas operaçôes, por outro lado eles trabalham sobre o mesmo objeto com um objetivo comum; quanto à ajuda mútua, ela consiste tanto em auxiliar alguém quanto em fazer o trabalho em seu lugar. ${ }^{11}$ Essas categorias podem ajudar na análise das entidades coletivas, mas elas não lhes desenham os contornos; as entidades coletivas são "pertinentes", uma vez que, sem a instauração dessas relações, "isso não poderia funcionar"; a existência delas é essencialmente ligada às questōes de eficácia, as quais é preciso analisar em cada caso.

Assim, pudemos compreender que as reorganizações da atividade, à noite, em um serviço de neonatologia, respondiam às exigências das tarefas a realizar, bem como integravam o fato biológico de baixa de vigilância no meio da noite, por isso é, sobretudo no começo da noite, que as enfermeiras

${ }^{11}$ Benchekroun, T-H., Weill-Fassina, A. (2000) (Coord). Le travail collectif. Perspectives actuelles em ergonomie. Octarès Editions. 
maximizavam sua ajuda aos auxiliares de puericultura. Em outro lugar, constataremos que uma aide-soignante presente desde sete horas da manhã no serviço será dispensada, na medida do possível, das tarefas mais árduas entre 14 horas e 15 horas. Esses arranjos apenas são possíveis se cada um conhece o serviço, os doentes, o trabalho que ele deve fazer, se está "familiarizado" com a natureza e as pressões do trabalho dos outros, se pode avaliar as prioridades do momento, mantendo-se informado sobre a atividade no conjunto do serviço. Um simples corredor oferece numerosas referências visuais sobre o desenrolar do trabalho em um serviço, os carrinhos de cuidados ou de limpeza, indicando a natureza e o avanço das tarefas; ele pode também ser um lugar privilegiado de trocas, pois todo mundo ali se cruza, membros do pessoal assim como doentes e famílias; a área de serviço é também um lugar essencial de trocas.

De fato, os indivíduos têm sempre uma percepção global, uma representação sintética da situação de trabalho, e é a partir desta que eles colaboram, cooperam, solidarizam-se ou se afrontam, que eles avaliam o que pode ser vivido, pois o "trabalhar junto" é também um "viver junto". A combinação de elementos participando desses arranjos será sempre única.

\section{A configuração dos atos autorizados/proibidos é flutuante}

Em matéria de repartição do trabalho, funções e responsabilidades são atribuídas, formalizadas, reconhecidas em diversos referenciais e estatutos profissionais. No setor de cuidados em saúde, os atos profissionais são regularmente inventariados pelo que se pode chamar de "decretos de competência” (1984, 1993, 2001), os domínios de atividade das profissões são definidos por listas de exames, de atos ou de terapêuticas suscetíveis de serem prescritas. A história da profissão e da formação de cuidados de enfermagem mostra, aliás, o quanto cuidados médicos são valorizados relativamente aos cuidados de enfermagem realizados sem prescrição médica. ${ }^{12}$ Pode-se pensar que a gravidade das consequências de alguns atos, ou de atos que não foram feitos, pesa de uma forma particular sobre a concessão de responsabilidades e sobre os processos de delegação. Mas, como em toda atividade de trabalho, quando diferentes profissionais intervêm para a produção de um mesmo objeto, serviço ou resultado, encontram-se "encavalamentos". ${ }^{13}$

\footnotetext{
${ }^{12}$ Ripert, M-C. (2002). La formation d'infirmière: pour um profil d'exécutante ou pour un professionnalisme intelligent ? Mémoire de DESS APST, Université de Provence.

${ }^{13}$ N.T.: ou superposições.
} 
Cada protagonista, médicos, enfermeira, aide-soignante e agente de serviço, tem seu próprio saber, seu "centro da profissão"; os chefes de enfermagem velam, na medida do possível, pelo respeito às normas em matéria de efetivos e de qualificações, mas, no desenrolar das atividades, uma enfermeira pode ser conduzida a "deslocar" 14 uma aide-soignante para fazer gessos, um agente de serviço qualificado para fazer a higiene de pessoas idosas. A posição das aides-soignantes é provavelmente aquela que tende a um maior "desmembramento funcional", elas são, ao mesmo tempo, mandadas para o alto, as enfermeiras podem lhes delegar uma parte das atividades de "nursing", e para baixo, pois, por falta de agentes de serviço em número suficiente, elas são também obrigadas a assumir uma parte da limpeza; dito de outro modo, do ponto de vista da gestão de pessoas, "elas não fazem mais o que é previsto por seu estatuto". ${ }^{15}$

De forma geral, observa-se que a gestão coletiva dos imprevistos e das variabilidades da atividade apoia-se sobre as margens de tempo e de recursos que os indivíduos podem liberar na realização de sua atividade e sobre as escolhas que eles fazem para determinar as tarefas prioritárias. Esses deslizamentos são mais ou menos custosos em termos de risco, de responsabilidade e de cansaço, eles participam dos desenvolvimentos da polivalência já favorecida pelos sistemas de "tempo escolhido", mas até onde essas "aberturas das profissões” podem contribuir para a eficácia ou, ao contrário, revelarem-se como causas de problemas maiores? São todas essas questôes que a ideia de "relativa" pertinência das entidades coletivas aponta; sua existência é frágil, meio clandestina, sujeita ao consentimento de uns e de outros.

\section{Como considerar (ou analisar) as ECRP na gestão das atividades?}

A questão pode ser colocada do ponto de vista geral da definição das profissões da saúde ou do ponto de vista mais particular das práticas de gestão de pessoal.

Diante da falta de profissionais em certas categorias, modificações no compartilhamento das tarefas entre médicos e profissōes paramédicas estão atualmente em estudo. A reflexão sobre as transferências entre profissões paramédicas virá em um segundo tempo. A ideia é "regularizar práticas existentes não reconhecidas, evitar a implementação de organizações paralelas,

\footnotetext{
${ }^{14}$ N.T.: o autor joga com as palavras "brancard" (maca, no caso do hospital), "brancardier ( o enfermeiro que transporta o paciente numa maca) e o verbo "brancarder" (transportar um ferido numa maca). Aqui há um sentido de "transportar" um profissional, deslocando-o de sua função.

${ }^{15}$ Fouilleul, N., Matheron, G. (19--?). L'efficacité dans un service de neurologie : de multiples connexions à élucider. In Y. Schwartz. L'évaluation économique à l'épreuve des services. Rapport de recherche, Université de Provence.
} 
fontes de conflitos e de baixa qualidade dos cuidados, trazer um legítimo reconhecimento a alguns profissionais paramédicos". Mas, ao mesmo tempo, os textos que definem os contornos das profissōes e cooperaçôes ou "articulações" esperadas devem evitar definir, de forma estreita, conteúdos de profissão para se contentar em lhes descrever os contornos "em seus grandes princípios". ${ }^{16}$ Espera-se alargar, de modo formal e legal, a natureza dos atos transferidos aos "atores suscetíveis de aceitar o compartilhamento das tarefas", mas compilar atos excluirá, automaticamente, outros; daí a ideia de definir contornos de princípio. Essas redefinições de profissões terão incidências diretas sobre a emergência e a dinâmica das ECRP nas situações de trabalho concretas, em que medida é possível prefigurá-las?

Para a gestão de proximidade, toda a dificuldade consiste em favorecer a emergência e a relativa estabilidade das ECRP, garantindo o respeito aos procedimentos e às prescrições. No setor de construção civil, uma análise fina mostrou que, para responder aos eventos que surgem de forma imprevisível, como em toda situação de trabalho, a gestão de proximidade utiliza um modo de "prescrição imprecisa" que consiste em não descrever em detalhe todo o trabalho a fazer e todas as coordenações necessárias à realização da obra nos prazos fixados. Essa forma de prescrever dá lugar a um suporte individual e coletivo dos imprevistos e das pressões quando eles se apresentarem. ${ }^{17}$

As atividades de cuidados em saúde não são poupadas pelos modos gerenciais, ${ }^{18}$ aí também é questão de "gerenciamento por objetivos", mas como declinar um objetivo tal como o da saúde pública, como o decompor sem o perder de vista? E, sobretudo, como e em que condiçôes favorecer, preservar as ECRP, garantia da eficácia coletiva?

\section{Conclusão}

A abordagem ergológica da dimensão coletiva das atividades de trabalho obriga a operar dois deslocamentos epistemológicos fundamentais, da equipe formal para as entidades coletivas relativamente pertinentes, do trabalho prescrito e previsto para a atividade concreta. Não se pode, pois, compreender o "trabalho de equipe" sem procurar conhecer as ECRP que atuam nas situaçóes reais e sem aceitar confrontar-se, consequentemente, com o difícil problema do registro das atividades cuja resolução é, sempre, apenas provisória.

\footnotetext{
${ }^{16}$ Berland, Y. (2003). Coopération des professions de santé : le transfert des tâches et compétences. Rapport d'étape au Ministère de la Santé, de la Famille et des Personnes handicapées.

17 Duc, M. (2002). Le travail en chantier. Octarès Editions.

${ }^{18}$ Le Goff, J-P. (2003, maio). Contre les illusions du management. Soins, 46.
} 


\section{Referências}

Benchekroun, T-H., Weill-Fassina, A. (2000) (Coord.). Le travail collectif. Perspectives actuelles em ergonomie. Toulose: Octarès Editions.

Berland, Y. (2003). Coopération des professions de santé : le transfert des tâches et compétences. Rapport d'étape au Ministère de la Santé, de la Famille et des Personnes handicapées.

Charriaux, M-M., (19--?). Qualifications en procès. Situations de travail qualifiantes à Péchiney-Gardanne. Rapport de recherche. Université de Provence.

Doray, B, Clot, Y, Michel (19--?), A. La gestion à coeur : approche de l'efficacité dans le service de chirurgie cardiaque de la Pitié-Salpétrière. In Y. Schwartz. L'évaluation économique à l'épreuve des services. Rapport de recherche, Université de Provence.

Duc, M. (2002). Le travail en chantier. Octarès Editions.

Faïta, D. (1997). In Y. Schwartz. Reconnaissances du travail, pour une approche ergologique. (pp. 52-53). Paris: PUF.

Fouilleul, N., Matheron, G. (1996). Construction collective de l'efficacité dans une unité de soins. Gestions hospitalières, 360, 668-672.

Fouilleul, N., Matheron, G. (19--?). L'efficacité dans un service de neurologie : de multiples connexions à élucider. In Y. Schwartz. L'évaluation économique à l'épreuve des services. Rapport de recherche, Université de Provence.

Guérin, F., Laville, A., Daniellou, F., Duraffourg, J. \& Kerguelen, A. (1991, 1997) Comprendre le travail pour transformer. Lyon: Editions de L'anact.

Le Goff, J-P. (2003, maio). Contre les illusions du management. Soins, 46.

Matheron, G. (2000). L'accueil et la médiation à l'hôpital: les aports du dispositif Nouveaux Services-Emploi Jeunes. L'exemple de l'hôpital Nord à Marseille. Mémoire de l'ENSP.

Peneff, J. (1992). L'hôpital en urgence. Paris: Editions Métailié.

Ripert, M-C. (2002). La formation d'infirmière: pour um profil d'exécutante ou pour un professionnalisme intelligent ? Mémoire de DESS APST, Université de Provence. 
Schwartz, Y. \& Durrive, L. (2003). In Y. Schwartz, L. Durrive (Orgs.), Travail et ergologie. Entretiens sur l'activité humaine. (pp. 141-157). Toulose: Octarès Editions.

\section{Precisão:}

Este artigo faz referência a trabalhos conduzidos no quadro do Instituto de Ergologia da Universidade de Aix-Marseille, há 30 anos especializado em análise pluridisciplinar das situações de trabalho (APST). 